\title{
The Phenomenon of Human Mind Slip in Rapid Writing Chinese Characters
}

\author{
Xiaoying Zhou ${ }^{1}$ \\ ${ }^{1}$ School of Foreign Languages, Nanchang Normal University, Nanchang, China \\ Correspondence: Xiaoying Zhou, School of Foreign Languages, Nanchang Normal University, Nanchang, China
}

Received: February 27, 2019 Accepted: April 4, 2019 Online Published: April 7, 2019

doi: 10.5539/elt.v12n5p66 URL: https://doi.org/10.5539/elt.v12n5p66

\begin{abstract}
The slip-over phenomenon is a very interesting feature in rapid writing Chinese characters, a unique psychological phenomenon in Chinese language. Most of the slip-over characters appear in set phrases. It is just like a walking man, when he is in a hurry he would sometimes run one or two steps. Since most Chinese characters contain radicals, slip-over phenomenon occurs quite frequently. In this paper the author lists four groups of slip-over characters and analyzes their psychological processes. The author holds that this study is useful, in some ways, in their use in computers.
\end{abstract}

Keywords: the slip-over phenomenon, human mind slip, rapid writing, Chinese characters, slip-over characters, psychological processes

\section{Introduction}

By slip-over in writing Chinese characters refers to the fact that when writing Chinese characters, which are composed of two parts with one part as the radical. The writer often subconsciously puts one part (the left part) or the whole part of the former character and the other part (the right part) or the whole part of the latter character into one, forming a new "character", which is composed of the corresponding parts of the former two characters in its form. This "character" is often not available in Chinese dictionaries or possesses completely new meaning, different from the original two characters. This is a unique psychological phenomenon in writing Chinese characters, especially those with radicals. In rapid writing such characters people often meet with such cases. Of course, this kind of slip-over characters should never appear in printed matters. But in informal writing or in taking notes or in inputting Chinese characters into computers we may as well try to use them as a way to save time and energy.

\section{What Is the Phenomenon of Human Mind Slip?}

Some Chinese people often meet with a strange phenomenon in writing Chinese. i.e. They often put two-character phrases into one character forming a new "character", which either bears the meaning different from that of the original character or can not be found in Chinese dictionaries.

The human mind slip-over phenomenon is a very interesting feature in writing Chinese characters, a unique psychological phenomenon in Chinese language. Nowadays we often talk about saving time, in writing Chinese characters if we can invent a set of such characters and put them into computers in suitable context, they can be correctly explained with little difficulties. And in case we need to write Chinese characters in a rapid speed this kind of characters are a good way to save time and energy. Some Chinese people often meet with a strange phenomenon in writing Chinese, i.e. they often put two-character phrases into one character, forming a new "character", which either bears the meaning different from that of the original character or can't be found in Chinese dictionaries. For example: some students often write 反对 (opposition) as 反寸 (fancun), or 江西 (the name of a province in China) as 工西 (gongxi) etc. This is a very interesting psychological phenomenon, unique in Chinese language. In the author's long-term translation and writing teaching processes, the author often meets with such slip-over phenomenon. Therefore the author notes them down whenever she meets them and puts them in order for analysis. The author finds that it embodies many interesting things and worthy a deep-going study. Most of the slip-over characters appear in set phrases. It is just like a walking man, when he is in a hurry he would sometimes run one or two steps. Since most Chinese characters contain radicals, slip-over phenomenon occurs quite frequently (Cai, 1991). 
For example: 厦门是一个美丽的地方 (Xiameng is a beautiful place).

When the writer writes this sentence he is most probably to write the two characters 厦门 (the name of a city in Fujian province in China) as 厂门 (changmeng). Why? Because when he is writing these two characters his mind focuses on the place rather on these two characters. Thus when he writes 厦(xia), he omits its 夏 (xia) and instantly slips over to the character 门(meng), forming the character 厂门 (changmeng). Although the character 厂门 (changmeng) means a factory door. In this sentence it can never be thus explained except the name of a city in China (Yang \& Wen, 1994).

According to the above examples we know that in the three-character phrases, if the latter two characters are composed of two parts with one part as the radical, then these latter two characters will most probably be written in slip-over characters. Whether the slip-over characters are made-up ones or not they possess the meaning of the two characters of the three-character phrase. Here the phenomenon of human mind slip is very obvious.

\section{The Phenomenon of Human Mind Slip in Rapid Writing Chinese Characters}

Nowadays we often talk about saving time. In writing Chinese characters if we can invent a set of such characters and put them into computers in suitable context, they can be correctly explained with little difficulties. And in case we need to write Chinese characters in a rapid speed this kind of characters are a good way to save time and energy. As a matter of fact, most of the Chinese phrases can be written in such slip-over characters.

Let us for example put the famous Chinese poet Li Bei's popular poem 静夜思 (Night Thoughts) in slip-over characters. The poem goes like this:

床前明月光, 疑是地上霜; (Chuangqian ming yue guang, yi shi di shang shuang)

举头望明月, 低头思故乡。(Jutou wang ming yue, di tou si gu xiang)

The poem written in slip-over characters is like this:

床前月光, 疑是地上霜; (Chuangqian yue guang, yi shi di shang shuang)

举头望明, 低头思古乡。(Jutou wang ming, di tou si gu xiang)

In rapid writing Chinese characters, the phenomenon of human mind slip often occurs. For the purpose of explicating this problem in details, let us explore the psychological state in writing Chinese characters. Take the frequently used phrase 哲学家 (philosopher) as an example, let us analyze its psychological process in writing this phrase. As is known to all, Chinese characters are square in form, combining sound, meaning, and form into one, among which sound and meaning compose its conception and the form is the requirement in writing. The following are some examples showing the concrete slip-over process in writing Chinese characters:

Another example : when we are writing the following sentence “鹦鹉能模仿人说话” (Yingwu neng mofang ren shou hua), as the phrase 财武 (parrot) is frequently used it is often quite possible to write it as 婴武 (Yingwu), the slip-over process is as follows:

When the writer writes 财鹉, his mental attention is focused not. The following are some examples on its two characters 鸭 (ying), 鹉 (wu), but on its meaning as a whole. Therefore in writing this phrase it's better for us to say that before writing 鸭鹉 (yingwu) the phrase appears in the writer's mind than to say that the conception of the phrase appears in the writer's mind. For the two characters 樱乌 (ying), 武 (wu), and its meaning (parrot) have formed its conception in the writer's mind before writing the phrase. At this time, the mental activity of the writer assumes it to be one "character" rather than two. And what is more, in the phrase 鹏武 (yingwu) the two characters 财 (ying) and 武 (wu) are all composed of two parts with one part as its radical, i.e. 婴 + 鸟二鸭 (ying+niao=ying), 武 + 鸟=武 $(\mathrm{wu}+\mathrm{niao}=\mathrm{wu})$. Therefore when the writer finishes writing the radical 贞 (ying) of the character 樱鸟(ying) he would subconsciously omit its part 鸟 (niao) and with the radical 婴 (ying) of the character 鸭(ying) replacing the radical 鸟 (niao) of the character 鹉 (wu), he slips over to 武 (wu) of the next character, resulting in a strange character 婴武 (yingwu). From here we can see that the association resulting from the character is another factor to cause slip-over. Thus the above sentence “鹦武能模仿人说话” (Yingwu neng mofang ren shou hua), is written as “贞武能模仿人说话” (Yingwu neng mofang ren shou hua). Interesting enough a "careless" reader often can not discover this slip-over "mistake".

As a matter of fact, most of the Chinese phrases can be written in such slip-over characters. This is a unique psychological phenomenon in writing Chinese characters, especially those with radicals. In rapid writing such characters people often meet with such cases.

For example:

条件反射 (conditioned response) 
When the writer writes this phrase his attention is not focused on the four characters 条件反射 (conditioned response), but break them into two phrases with independent meanings, i.e. 条件 (condition) and 反射 (response). And when he writes 条件反射 (conditioned response), he would be very easily to write it as 条件 反寸 (Tiaojian fa cun) or even 条牛反寸 (tiao niu fan cun). The psychological process is as follows: when the writer is writing the set expression 条件反射(conditioned response), they often write them as 条件反寸 (tiaojian fan cun), in which the character 反寸(fan cun) is the result of slip-over in writing 反射 (response), i.e. they slip from the character 反 (opposition) over to the character 射 (projection), resulting in a slip-over character 反寸(fan cun). Thus 反射 (response) is written as 反寸 (fan cun). This is a slip-over phenomenon in writing Chinese characters, a unique psychological phenomenon in Chinese language. The research of this phenomenon can not only reveal the psychological state of the writer while writing the character but also make one think of many other things connected with it.

The above examples are just a few cases among many. Actually there are many such examples in writing Chinese characters. In order to further explain this phenomenon, the author gives a more detailed explanation in the following section: classification of the slip-over phenomenon

Generally speaking, the psychological phenomenon of the slip-over in writing Chinese characters can be divided into the following groups:

\section{(1) Group one}

In this group are included some three-character phrases, in which the latter two characters are written as slip-over characters. In rapid writing Chinese characters, slip-over phenomenon often occurs. Take the frequently used phrase 哲学家 (philosopher) as an example let us analyze its psychological process in writing this phrase. As is known to all, Chinese characters are square in form, combining sound, meaning and form into one, among which sound and meaning compose its conception and the form is the requirement in writing. The following are some examples showing the concrete slip-over process in writing Chinese characters:

For example when we are writing the following Chinese sentence: “老子是中国古代哲学家” (Laozi is a Chinese ancient philosopher), as the phrase 哲学家 (philosopher) is frequently used it is often quite possible to write it as 哲家 (ze jia). The slip-over process is as follows:

When the writer writes 哲学家 (philosopher), his mental attention is focused not on its three separate characters 哲 (ze), 学 (xue), 家 (jia), but on its meaning as a whole. Therefore in writing this phrase it is better for us to say that before writing 哲学家 (philosopher) the phrase appears in the writer's mind than to say that the conception of the phrase appears in the writer's mind. For the three characters 哲 (ze), 学 (xue) and 家 (jia) and its meaning (philosopher) have formed its conception in the writer's mind before writing the phrase. At this time, the mental activity of the writer assumes it to be one "character" rather than three. And, what is more, in the phrase 哲学家 (philosopher), the two characters 学 (xue) and 家 (jia) are all composed of two parts with one part as its radical, i.e. when the writer finishes writing the character 哲 (ze), he would subconsciously omit the character 学 (xue), and slip over to the character 家 (jia). Thus the above sentence: “老子是中国古代哲学 家” (Laozi is a Chinese ancient philosopher) is written as : “老子是中国古代哲家” (Laozi shi zhongguo gudai ze xue). Interesting enough, a "careless" reader often can not discover this slip-over "mistake". Here the phenomenon of human mind slip is very obvious whether the slip-over characters are made-up ones or not they possess the meaning of the two characters of the three-character phrase.

\section{(2) Group two}

In the three-character phrases, if the middle character with the character before or after it does not have independent meaning and if it is a two-part character also, then sometimes human mind slip would fall upon the first two characters, the formula being as follows:

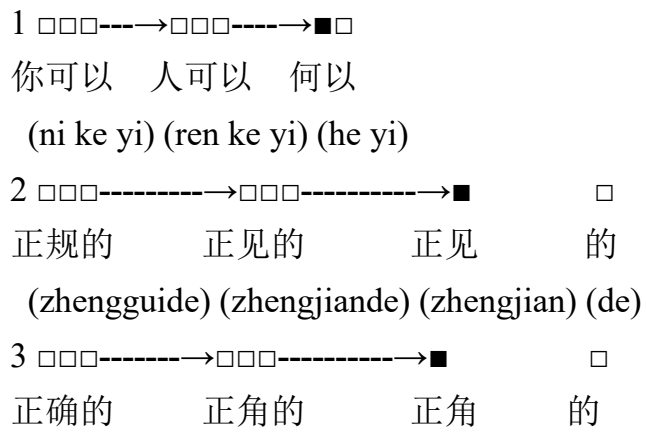


(zhengquede) (zhengjiaode) (zhengjiao) (de)

For example, they often write 活泼 (active) as 舌发 (shefa), or 猛烈的 (violent) as 孟列的 (mengliede). Another example: when some students are writing 消沉 (low-spirited), they often write them as 肖沉 (xiaochen), in which the character 肖沉 (xiaochen) is the result of slip-over in writing 消沉 (low-spirited). Another example, when they are writing 惊讶 (amazed), they often write them as 京牙 (jingya), in which the character 京牙 (jingya) is the result of slip-over in writing 惊讶 (amazed), i.e. they slip from the character 惊 (jing) over to the character 京 (jing), and slip from the character 讶(ya) over to the character 牙 (ya), resulting in a slip-over character 京牙 (jingya). Thus 惊讶 (amazed) is written as 京牙 (jingya). This is a slip-over phenomenon in writing Chinese characters, an unique psychological phenomenon in Chinese language. The research of this phenomenon can not only reveal the psychological state of the writer while writing the character but also make one think of many other things connected with it.This is a very interesting psychological phenomenon, unique in Chinese language. In her long-term translation and writing practice, the author often meets with such slip-over phenomenon. The author finds that it embodies many interesting things and worthy a deep-going study. The present paper is just the result of such study.

For example: 桂林山水甲天下 (Guilin shan shui jia tian xia)

When the writer writes this sentence she is most probably to write the two characters 桂林 (the name of a city in Guangxi in China) as 圭木 (guimu). Why? Because when she is writing these two characters her mind focuses on the place rather on these two characters. Thus when she writes 桂 (gui), she omits its 木 (mu) and instantly slip over to the character 圭 (gui), forming the character 木 (mu). When she writes 林 (lin), she writes only one 木 $(\mathrm{mu})$, and omits another 木 $(\mathrm{mu})$.

There are many such examples in writing Chinese characters. In order to further explain this phenomenon, the author gives other examples. Below are included some three-character phrases, in which the latter two characters are written as slip-over characters. It can be formulated like this:

an口- $\rightarrow \square$
科学家 科
(kexuejia) (ke) (ke)
正规的 正 $\quad$ 正
(zhengguide) (zheng) (zheng)
正确的 正 正
(zhengquede) (zheng) (zheng)

In the above example 你可以 (you may) is written as 何以 (heyi), which means "why". It is really a coincidence. But if put into the context it can be explained as 你可以 (you may) but not in other ways.

(3) Group three

This is a frequently-occurred slip-over group, which contains many two-character phrases (or at least one character containing two parts). It can be formulated like this:

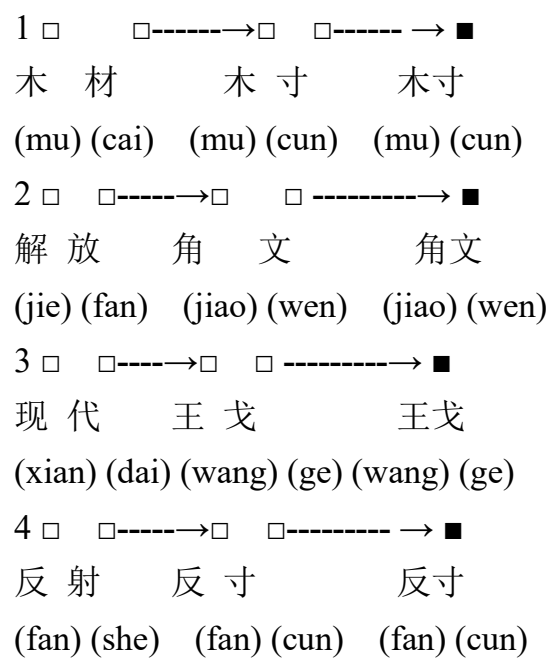




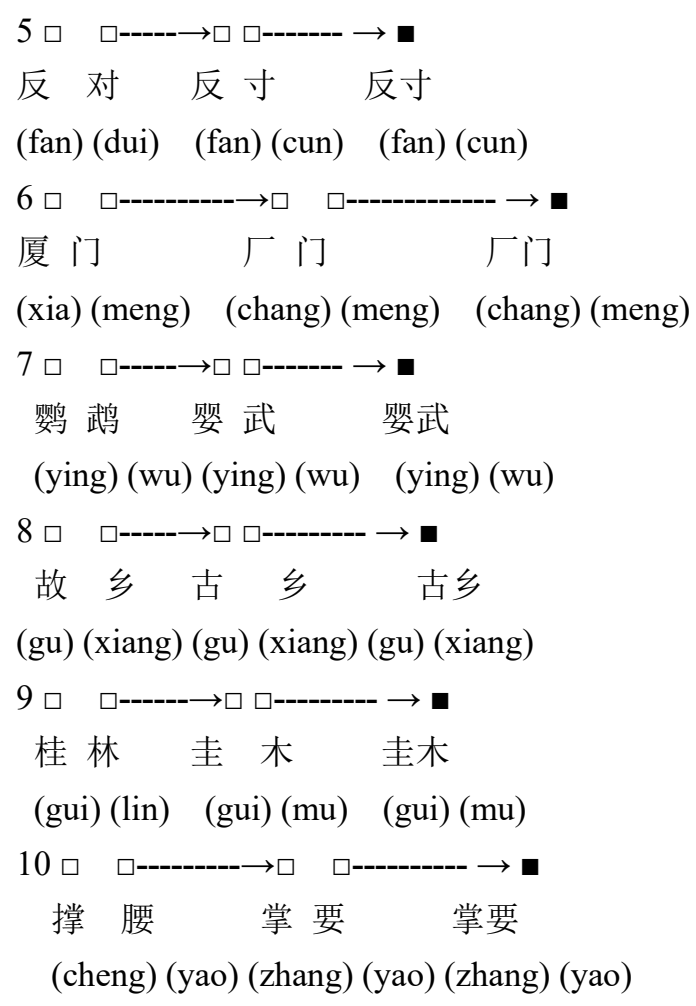

According to the above examples, the slip-over characters 角文 (jiaowen) and 王戈 (wange) have no meaning of their own and can not be found in Chinese dictionaries. It should be mentioned that when 木 (mu)and 材 (cai) are written in slip-over characters they are not written as 材 (cai), which is just the second character of the phrase, but with slight change. It becomes 村 (village). This means that human mind tends to replace abstract meaning with concrete meaning of things. And besides, the slip-over character 反寸 (fancun) can be explained as 反射 (response) or 反对 (opposition), whose meaning depends on the context it appears.

Why does the writer write 厦门 (Xiameng), (the name of a city in China) as 厂门 (the door of a factory)? Because when he is writing these two characters his mind focuses on the name of the place, rather on these two characters. Thus when he writes the 厦门 (Xiameng), he omits its 夏 (xia) and instantly slips over to the character 门 (meng), forming the character 厂门 (chang meng). In diagram it can be explained like this:

厦门 $\rightarrow$ 厦门

(xiameng) (xia) (meng)

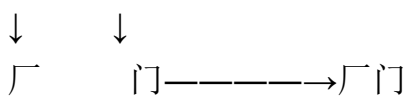

(chang) (meng) (chang) (meng)

Although the character厂门 (changmeng) means the door of a factory, in this sentence it can never be thus explained except the name of the city.

The above examples are just a few cases among many. Actually there are many such examples in writing Chinese characters. Of course, the readers can find many other examples. The author does not explain it in details here.

(4) Group four

Some four-character phrases sometimes can be written in slip-over characters if they contain two-part characters. In this way the two-part characters can be written in slip-over characters. The following is a formula:

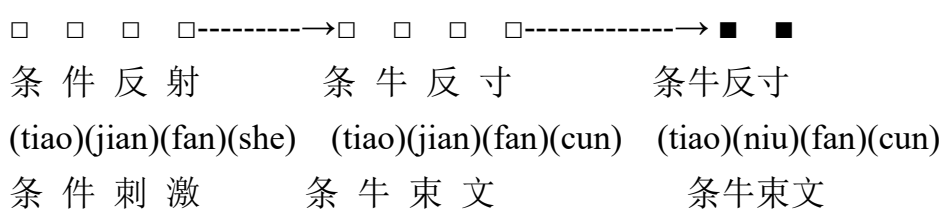




\section{(tiao)(jian)(ce)(ji) (tiao)(niu)(shu)(wen) (tiao)(niu)(she)(wen)}

When the writer writes this phrase his attention is not focused on the four characters 条件反射 (conditioned response), but break them into two phrases with independent meaning, i.e. 条件 (condition) and 反射 (response). And when he writes 条件反射 (conditioned response),, he would be very easily to write it as 条件反 寸 (tiao jian fan cun) (or even 条牛反寸 (tiao niu fan cun)). The psychological process is as follows:

条 件 反射---------- $\rightarrow$ 条 件 反 射

(tiao)(jian)(fan)(she) (tiao)(jian)(fan)(she)

$$
\begin{aligned}
& \downarrow \downarrow \\
& \text { 反 } \rightarrow \text { 反寸 } \\
& (\text { fan)(cun) } \quad(\text { fan) (cun) (Zhang, 1981) }
\end{aligned}
$$

It can be seen from here that 反寸(fan cun) is a new "character", not available in Chinese dictionaries. Here the form of the character 反(fan) has not changed, but under the influence of the phrase 反对 (opposition) the writer does not put his mental attention on the phrase 反射 (response). Thus he is most likely to write it as 反寸 (fan cun). Judging from its appearance the slip-over character can be explained as 反射 (response) and 反对 (opposition). However if it appears in the context, it can only be explained as 条件反射 (conditioned response), not 条件反对 (conditioned opposition).

We can see from these examples that human mind experiences two slip-over processes in writing this kinds of phrases, which is really a very interesting way in writing Chinese characters. Here the phenomenon of human mind slip is very obvious.

\section{Summary}

This paper is a study of the slip-over phenomenon in writing Chinese characters, a feature unique in Chinese language. We discuss the phenomenon of human mind slip in rapid writing Chinese characters. Most of the slip-over characters appear in set phrases. Since most Chinese characters contain radicals, slip-over phenomenon occurs quite frequently. As we often write in horizontal lines, characters with two parts, one beside the other, may most likely be written in slip-over characters. As to the characters with one part above the other they may mostly be written in vertical slip-over characters as we mentioned above. There is a very popular Fortune Poster on traditional Chinese festivals. It is written like this:

$$
\begin{aligned}
& \text { / 黄(huang) । } \\
& \text { / 金(jin) \ } \\
& \text { 万(wan) / }
\end{aligned}
$$

It is an arbitrary use of the vertical slip-over characters, because the character 黄金万 (huang jin wan) means 黄 金万两 (ten thousand Lian of gold), a four-character phrase with three slip-over characters (Cai, 1991).

The slip-over phenomenon is a very interesting feature in writing Chinese characters, a unique psychological phenomenon in Chinese language. Nowadays we often talk about saving time. In writing Chinese characters if we can invent a set of such characters and put them into computers in suitable context, they can be correctly explained with litter difficulties. And in case we need to write Chinese characters in a rapid speed this kind of characters are a good way to save time and energy. As a matter of fact, most of the Chinese phrases can be written in such slip-over characters. Of course, this kind of slip-over characters should never appear in printed matters. But in informal writing or in taking notes or in inputting Chinese characters into computers, we may as well try to use them as a way to save time and energy. One thing to mention is that we should by no means invent such characters arbitrarily, for invented slip-over characters, if not used in suitable context, may cause confusions.

\section{References}

Ajzen, I. (2015). The theory of planned behavior is alive and well, and not ready to retire; A commentary on Sniehotta, Pressear, and Araujo-Soares. Health Psychology Review, 9, 131-137. https://doi.org/10.1080/ 17437199.2014.883474

Aperocho, M. (2016). Lexical and syntactic features of the male and female students argumentative essays. University of Min. Intl. Mult. Res. Journal, I(1), 213-226

Cai, Y. (1991). Writing Process and Writing Ability. Modern Foreign Languages, 4, 52-59.

Christie, F. (2012). Language Education Throughout the School Year. Malden: Wiley. 
Coffin, C., \& Donohue, J. (2014). A Language as Social Semiotic Based Approach to Teaching and Learning in Higher Education. Malden: Wiley.

Ernest, C. (1946). Language and Myth. In Y. Xiao (Translated), San Lian Shu Dian (pp. 129-201). Beijing, China.

Jiwon, H., \& Phil, H. (2018). Genre-based L2 writing instruction and writing-specific psychological factors: The dynamics of change. Journal of Second Language Writing, 40, 44-59. https://doi.org/10.1016/j.jslw.2018. 03.001

Liu, Z. W. (1982). Five Lectures on Chinese Poetry (pp. 56-59). The Foreign Language Teaching \& Research Press, Beijing.

Pang, M. (2016). Companion guides for lesson planning: A planning template and the lesson pro forma. ELT Journal, 70(4), 444-454. https://doi.org/10.1093/elt/ccw053

Ruan, S. (1994). The Significance of Proper Noun. Learned Journal of Eastern China Normal University, 5, 69-87.

Shi, Y. Z. (2007). Compositionality of Language Competence: Evidence from Cognitive Psychology. Studies in Language and Linguistics, 3, 59-68.

Sennet, A. (2011). Unarticulated constituents and propositional structure. Mind \& Language, 4, 412-435. https://doi.org/10.1111/j.1468-0017.2011.01423.x

Stanley, J. (2002). Making it articulated. Mind and Language, 1, 149-168. https://doi.org/10.1111/14680017.00193

Terence, H. (1977). Structuralism and Semiotics (pp. 138-139). University California Press. Berkeley, California. USA.

Tu, J. L. (1988). Selected Works of Famous Linguistics Philosophical Works (pp. 198-200). San Lian Shu Dian. Beijing. China.

Yang, Y. C., \& Wen, Z. R. (1994). An Analysis on Sentence Types and Structures in Chinese Students' English Writing. Modern Foreign Languages, 5, 28-33.

Zhao, Y. Q. (1995). From Written Discourse to Teaching of Reading. Modern Foreign Languages, 1, 36-41.

Zhang, J. (1981). An Outline of Comparative Grammar between English and Chinese (pp. 35-41). Commercial Press, Beijing.

Zhang, Z. C. (1995). An Account of the Psychological Process of Writing for Chinese Learners of English. Modern Foreign Languages, 10, 62-69.

\section{Copyrights}

Copyright for this article is retained by the author(s), with first publication rights granted to the journal.

This is an open-access article distributed under the terms and conditions of the Creative Commons Attribution license (http://creativecommons.org/licenses/by/4.0/). 